\title{
Application of Structural Damage Control in Seismic Performance Opti- mization of Long-span Cable-stayed Bridge
}

\author{
Ning Wan*
}

Southwest Jiaotong University-Emei, Emei, Sichuan, 614202, China

\begin{abstract}
The damage caused by earthquake is irresistible for human beings, and the structure with poor robustness is most affected by earthquake. Especially when traffic arteries like bridges and highways are affected, the losses will be unimaginable. To reduce the loss in earthquake, the paper targets the long-span cable-stayed bridge and discusses a method of structural damage control. The energy-dissipation auxiliary pier structure can protect the bridge under strong shock, which has an important realistic significance for reducing losses of the bridge. The model of auxiliary pier is built in the paper. Through the experiment, many aspects including destructive process, hysteretic characteristics, ductility and hysteretic energy, equivalent viscous damping ratio and deforming capacity of energy-dissipation construction are analyzed. Structural damage control can well enhance the safety of bridge. The internal force and displacement of main components can be reduced correspondingly, and thus the safety of long-span cable-stayed bridge is well protected.
\end{abstract}

Keywords: Cable-stayed bridge, control, seismic performance, structural damage.

\section{INTRODUCTION}

As the traffic is increasingly developed today, the role of long span bridge is becoming more and more important. However, influenced by earthquake [1-3], the structural displacement may happen, the components may be seriously damaged and even the bridge may collapse [4], which could be seen in many examples before. Based on this, the paper puts forward the method of structural damage control just as follows:

\section{CONCEPT AND ENGINEERING BACKGROUND OF STRUCTURAL DAMAGE CONTROL}

The so-called structural damage control is actually a control method of using secondary components to consume the energy of earthquake in order to protect the safety of principal components [5]. Besides, the structural system with a reliable energy dissipation mechanism designed according to the concept will be of profound significance for the earthquake resistance of long span bridge.

In this paper, the background engineering is a cablestayed bridge of symmetrical structure [6-9], with the total length of $2.672 \mathrm{~km}$ and the main span length of $1.4 \mathrm{~km}$. it is still in the stage of trial design. Seven spans are designed in the bridge, specifically including: $0.15 \mathrm{~km}+0.176+\mathrm{km}+$ $0.31 \mathrm{~km}+1.4 \mathrm{~km}+0.31 \mathrm{~km}+0.176 \mathrm{~km}+0.15 \mathrm{~km}$. Meanwhile, two auxiliary piers and one transitional pier are set in both sides of the bridge, with the height set as $0.06 \mathrm{~km}$. In Figs. (1-3) are the auxiliary piers, and No 1 is the transitional pier. As is shown in Fig. (1), the cable-stayed bridge adopts the floating architecture. The height of its main tower is set as $0.357 \mathrm{~km}$ and shaped as A. There are totally 333 stayed cables pulled from the spire to the bridge floor, distributed like a semi harp. The steel box girder is the main beam, with its width and height respectively set as $0.041 \mathrm{~km}$ and $0.0045 \mathrm{~km}$.

\section{MODEL DESIGN}

In the paper, three auxiliary pier models are designed, and all of them are of high range. As is shown in Fig. (2), we can see the section and elevation view of specimen, with the height set as $6 \mathrm{~km}$. the rectangular section of hollow ferroconcrete is used, with its wall thickness set as $15 \mathrm{~cm}$, the longitudinal steel ratio set as $1.7 \%$ and the transverse reinforcement ratio of stirrup set as $1.2 \%$. The first specimen is set as single-column pier-specimen SRC. The other two specimens are set as double-column piers, with two pier columns set along the longitudinal bridge. The energydissipation components are installed between pier columns, and these components are made by means of mild steel. Meanwhile, the second specimen (specimen TRC-SL) adopts the shearing-type connecting rod as the energy dissipation component [10,11]. The third specimen (specimen TRCBRB) adopts the buckling-restrained brace as energy dissipation component. The specimen that has finished pouring can be seen in Fig. (3).

The shearing-type connecting rode actually refers to the weld assembly I-steel made of Q235 steel, and compared with the rolling I-steel, it has more choices in the aspects including geometric dimension of steel plate and materials, which is more suitable for long-span bridge. As is shown in Fig. (4a), it is shearing-type yield components. Seen from Fig. (4b), the content composed of buckling-restrained brace includes: steel sleeve, cruciform core board and concrete packing materials filled between the core board and sleeve. A single layer of non-adhesive material can be smeared on the contact surface of core board and concrete, which makes 


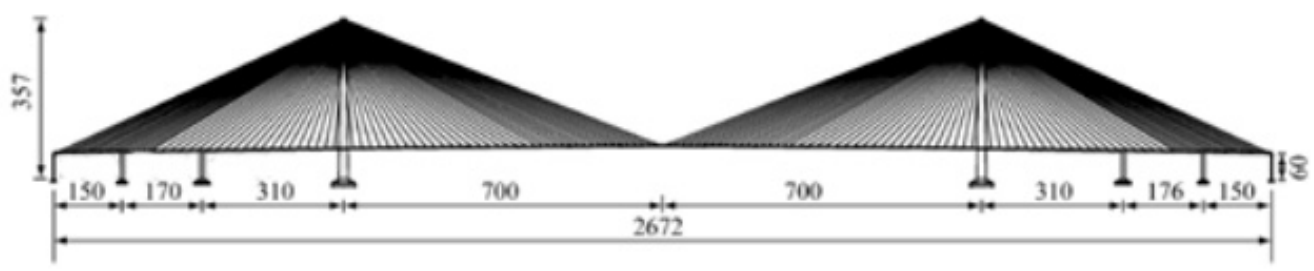

Fig. (1). Elevation View of Original Bridge (Unit: mm).

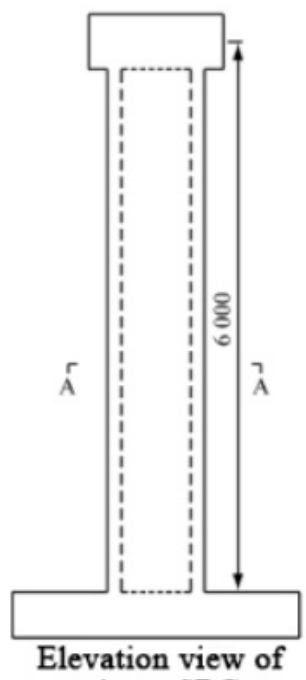
specimen SRC

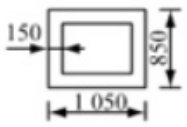

Section A-A

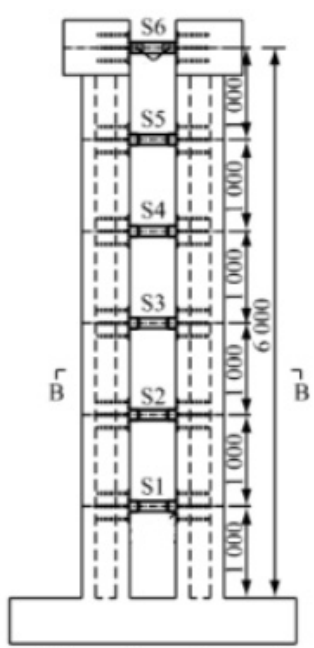

Elevation view of specimen TRC-SL

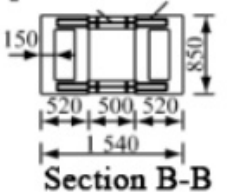

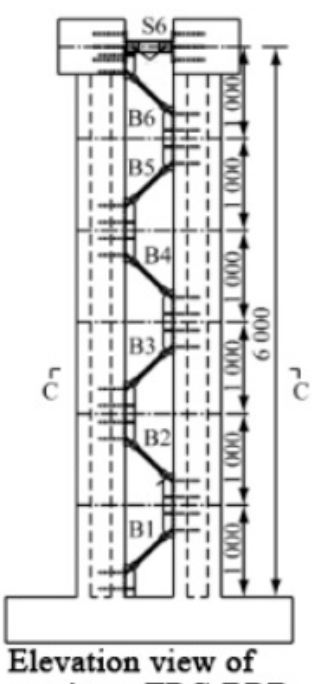

specimen TRC-BRB

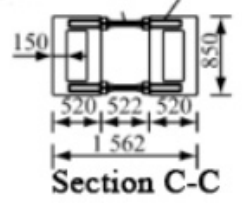

Fig. (2). Section and Elevation View of Specimen (Unit: mm).

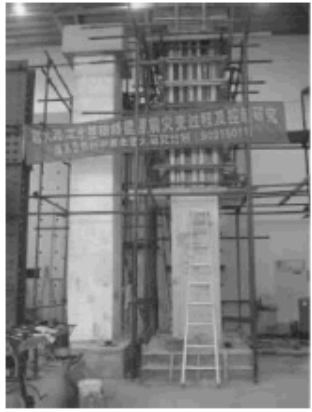

a SRC

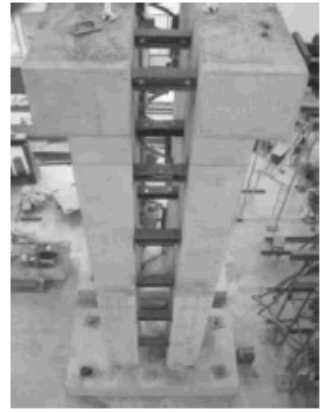

b TRC-SL

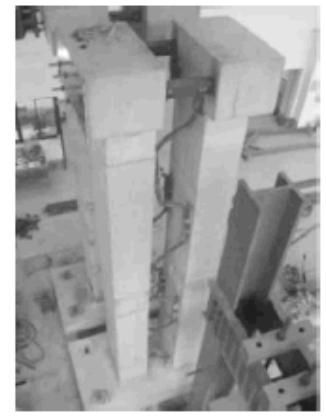

c TRC-BRB

Fig. (3). Pictures of Specimen.

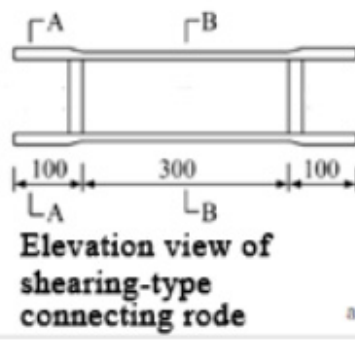

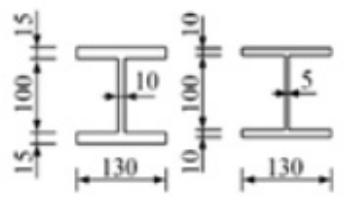

Section A-A Section B-B a SL.

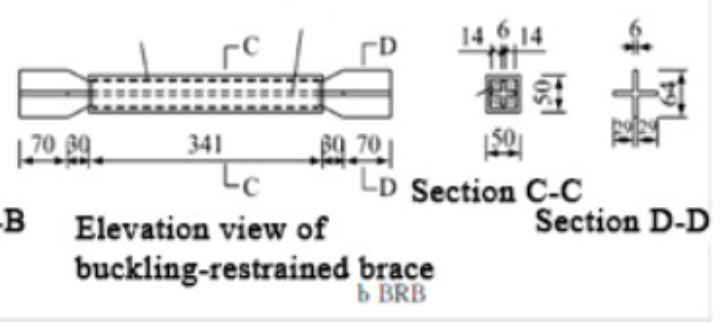

Fig. (4). Geometric Graphic of Energy Dissipation Components (Unit: mm). 
the steel plate of core board freely extend along the axial direction, so as to reduce the shear force transfer between core board and sleeve. The thickness of steel plate used in core board is $6 \mathrm{~mm}$, the length keeps same along the brace, and the width is gradually and gently enlarged in the bottom.

\section{TEST METHODS}

Since the real quality of these three specimens is quite heavy, it is difficult for the crane to hang and move them. So in the test, the pouring is directly conducted by segmentation on the test rig so as to complete the production of specimen. In order to imitate the $25 \mathrm{KN}$ axial force given by the topside structure, the method is to design a reinforced concrete mass block on the top of specimen. The quasi-static loading is adopted in the test. The base is fixed on the test rig through four foundation bolts. Then MTS servo system hydraulic actuator exerts a low cyclic loading in a horizontal direction. The Max thrust force exerted by the actuator is $1500 \mathrm{KN}$, the Max pulling force is $900 \mathrm{KN}$ and the Max stroke of displacement is $250 \mathrm{~mm}$, which equals that there happens a drift rate (ratio of the horizontal displacement of pier top to the loading height of pier column) of $4.2 \%$ on the pier top.

The loading mode of full displacement control is adopted in the test. The specific loading scheme is shown in Fig. (5). When the loading displacement level is before $30 \mathrm{~mm}$, there is $5 \mathrm{~mm}$ progressively increased level by level starting from the initial $5 \mathrm{~mm}$. after $30 \mathrm{~mm}, 10 \mathrm{~mm}$ is progressively increased until the longitudinal bar in pier column breaks. To facilitate the research on strength degradation of specimen, the loading frequency for repeating each displacement level is set as three times.

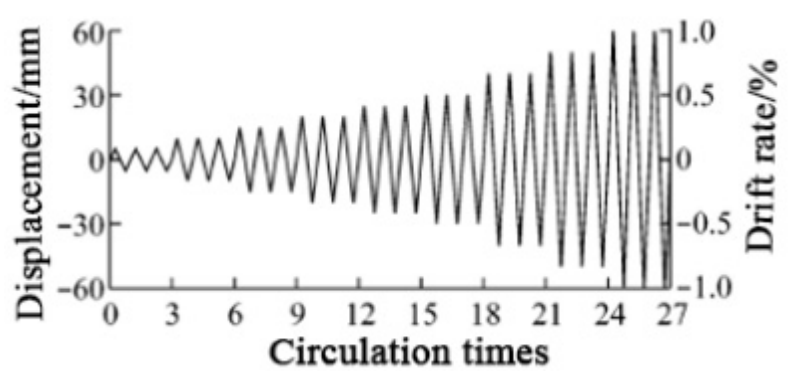

Fig. (5). Loading Scheme.

The transverse displacement of specimen is obtained by the displacement meter installed at each height. The strain value when the concrete cracks can be achieved by sticking the strain gauges on the steel bar and concrete surface and the energy dissipation component surface at the bottom of specimen. The occurrence of yield steel bar and energy dissipation component can be judged by means of the tested strain values. The average shearing deformation value $\gamma$ of shearing-type connecting rod can't be directly achieved, but the changes in value of diagonal length of rectangular connecting rod can be calculated by means of formula (1). The changes in value of diagonal length of connecting rod can be directly tested by the two displacement meters set along the diagonal direction. As is shown in Fig. (6), it is the geometrical relationship of average shearing deformation computation.

$$
\gamma=\frac{\left(\Delta d_{1}-\Delta d_{2}\right) \sqrt{a^{2}+b^{2}}}{2 a b}
$$

In this formula: $\Delta \mathrm{d} 1=\mathrm{d}^{\prime} 1-\mathrm{d} 1, \Delta \mathrm{d} 2=\mathrm{d}^{\prime} 2-\mathrm{d} 2$, are respectively the value changes of two diagonal lengths. The lengths of both sides of rectangular connecting rod are respectively set as A and B.

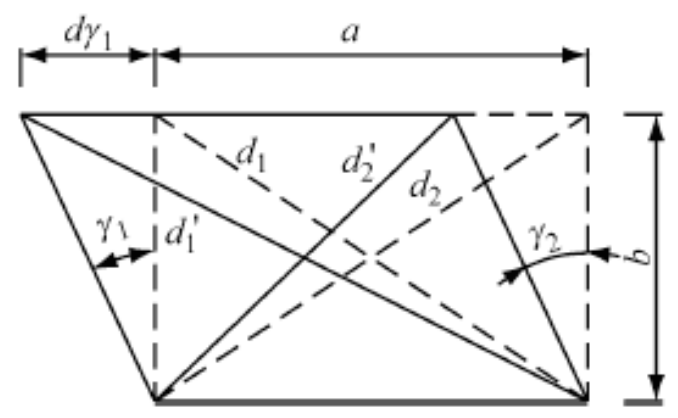

Fig. (6). Geometric graphic of average shearing deformation computation.

\section{ANALYSIS OF TEST RESULTS}

\subsection{Destructive Process and Phenomenon}

\subsubsection{SRC Specimen SRC}

When the loading displacement level is at $10 \mathrm{~mm}$ and the drift rate is $0.17 \%$, the concrete of specimen SRC starts to crack. Then the crack is concentrated on the range of $2 \mathrm{~m}$ height from the top face of base. When the yield occurs in the longitudinal bar at the bottom of pier, the displacement level is $40 \mathrm{~mm}$ and the drift rate is $0.67 \%$. Near the base at southwestern corner of the pier column, a little concrete starts to fall off, the displacement level is at $100 \mathrm{~mm}$ and the drift rate is $1.67 \%$. But the displacement level is increasingly loaded in order to test the maximum bearing capacity of specimen. The crack occurs, because the loading displacement level of three longitudinal bars at the east of specimen is at $190 \mathrm{~mm}$ and the drift rate is $3.17 \%$. At the moment, the bearing capacity of specimen descends rapidly till the test is over, as is shown in Fig. (7A).

\subsubsection{Specimen TRC-SL}

When the displacement is at $15 \mathrm{~mm}$ and the drift rate is $0.25 \%$, the concrete of specimen TRC-SL starts to crack and then the crack is concentrated in the range of $3 \mathrm{~m}$ height from the top face of base. When the connecting rode S5 (the fifth row starting from the base) starts to yield, the displacement is at $25 \mathrm{~mm}$ and the drift rate is $0.41 \%$. When the displacement is at $40 \mathrm{~mm}$ and the drift rate is 0.67 , the longitudinal bar starts to yield. When all of the connecting rods start to yield, the displacement is at $80 \mathrm{~mm}$ and the drift rate is $1.33 \%$. A little concrete in southwestern corner at bottom of west column starts to fall off, the displacement is at $170 \mathrm{~mm}$ and the drift rate is $2.83 \%$. As is shown in Fig. (7B), when the displacement is at $210 \mathrm{~mm}$ and the drift rate is $3.5 \%$, the connecting rod S5 cracks. The test goes on. As is shown in Fig. (7C), when the displacement is loaded at $240 \mathrm{~mm}$ and the drift rate is $4.00 \%$, four longitudinal bars in east side of eastern column of specimen crack. Then the test is over. 


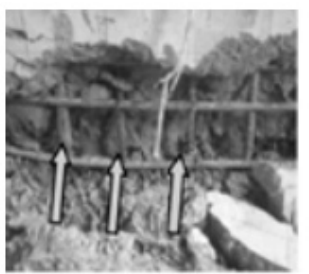

a Longitudinal bar of eastern SRC cracks

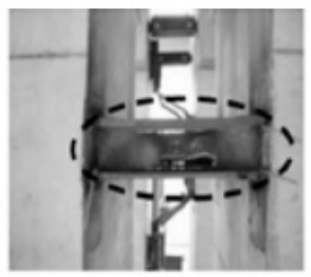

b S5 web of TRC-SL cracks

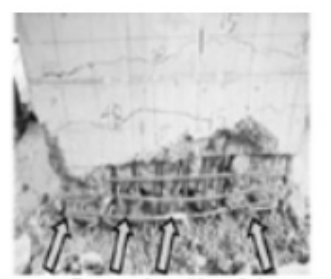

c Longitudinal bar of eastern TRC-SL cracks

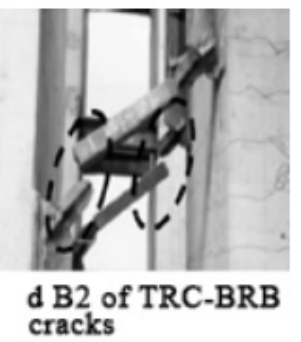

Fig. (7). Destructive forms of specimen.
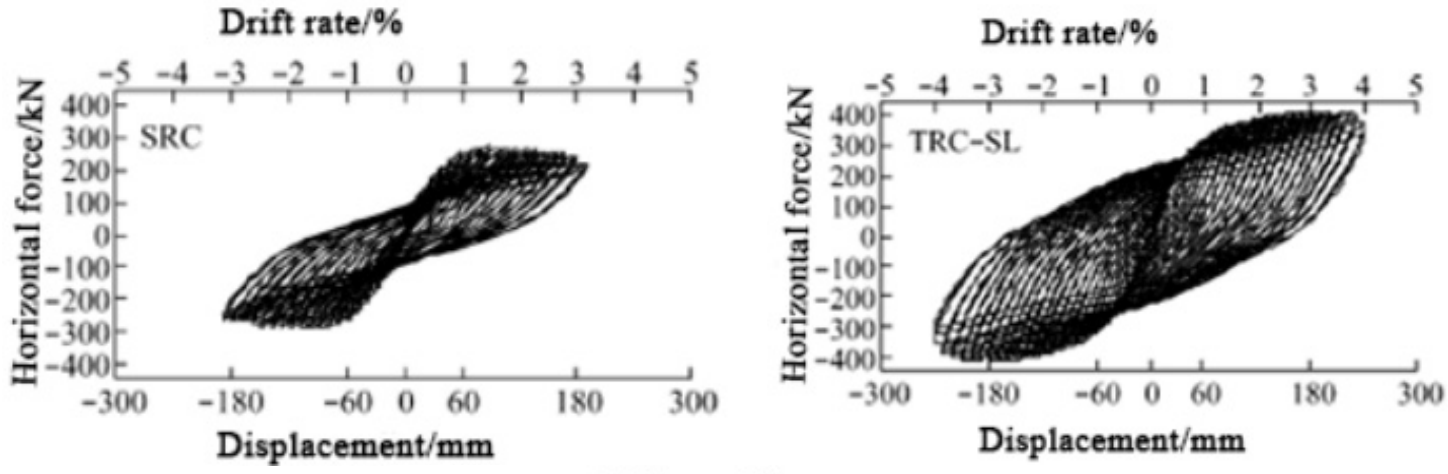

Drift rate $/ \%$

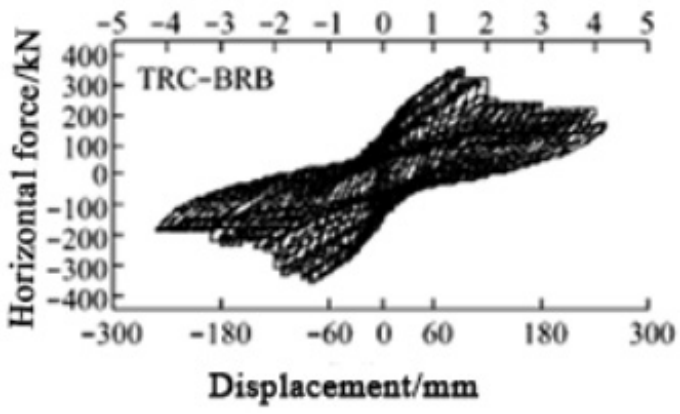

Fig. (8). Hysteretic Curve of Specimen.

\subsubsection{Specimen TRC-BRB}

When the displacement is at $20 \mathrm{~mm}$ and the drift rate is $0.33 \%$, the crack starts to occur in specimen TRC-BRB. Then the cracks are concentrated in the range of $3 \mathrm{~m}$ height from the top face of base, and yield starts to happen in brace B6, B5 and B4 (from the base are respectively the sixth, fifth and forth). When the longitudinal bar yields, the displacement is at $40 \mathrm{~mm}$ and the drift rate is $0.67 \%$; when all the braces yield, $50 \mathrm{~mm}$ and $0.67 \%$; when the brace B6 cracks, $120 \mathrm{~mm}$ and $1.83 \%$; when northern brace of B1 cracks, $190 \mathrm{~mm}$ and $2.00 \%$; when B2 cracks, $240 \mathrm{~mm}$ and $4.00 \%$ (as is shown in Fig. 7d). At the moment, the left B4 and southern brace of B1are still bearing while others all crack. But due to the maximum displacement stroke limitation of actuator, the test goes on and it is over when the displacement level is at $250 \mathrm{~mm}$ and the drift rate is $4.17 \%$. But there is no occurrence that concrete falls off from the protective blanket in bulk.

\subsection{Hysteretic Characteristics of Specimen}

The seismic performance of specimen is proportional to the plumpness of the hysteretic curve. As is shown in Fig. (8), before the concrete starts to crack, the loading and un- loading curves overlapped. The hysteretic curve is straight line. Specimen is in the flexible stage. After the concrete cracks, the area of hysteretic loop is gradually enlarged and the hysteretic energy is started. Then the energy dissipation components and longitudinal bars successively yield. The area of hysteretic loop is further enlarged and the capacity of energy dissipation is enhanced. For the double-column specimen TRC-SL and TRC-BRB, the energy dissipation components yield earlier than the longitudinal bar. The double-column pier starts the energy dissipation before the longitudinal bar yields.

\subsection{Ductility and Hysteretic Energy of Specimen}

In this test, the ultimate displacement of specimen is subject to the displacement when the longitudinal bar of pier column starts to crack. Specific hysteretic energy is calculated by totaling the area surrounded by all hysteretic loops. As is shown in Table 1, the displacement ductility factor of double-column pier is increased from 5.9 to 12.5 , and the hysteretic energy is increased from 1.11MN.m to 4.98MN.m. Compared with the single-column pier, the displacement ductility factor and hysteretic energy of double-column pier is significantly larger, so the energy dissipation components 
Table 1. Displacement ductility factor and hysteretic energy of specimen.

\begin{tabular}{|c|c|c|c|c|c|c|c|}
\hline Specimen & $\begin{array}{c}\text { Yield } \\
\text { displacement } \\
\boldsymbol{\Delta}_{\mathbf{y}} / \mathbf{m m}\end{array}$ & $\begin{array}{c}\text { Yield strength } \\
\mathbf{P}_{\mathbf{y}} / \mathbf{k} \mathbf{N}\end{array}$ & $\begin{array}{c}\text { Ultimate } \\
\text { displacement } \\
\boldsymbol{\Delta}_{\mathbf{m}} / \mathbf{m m}\end{array}$ & $\begin{array}{c}\text { Ultimate } \\
\text { displacement } \\
\mathbf{P}_{\mathbf{m}} / \mathbf{K N}\end{array}$ & $\begin{array}{c}\text { Maximum } \\
\text { displacement duc- } \\
\text { tility factor } \boldsymbol{\mu} \boldsymbol{\Delta}\end{array}$ & $\begin{array}{c}\text { Hysteretic energy } \\
\mathbf{E D} / \mathbf{m N} \cdot \mathbf{m})\end{array}$ & $\begin{array}{c}\text { Maximum drift } \\
\mathbf{r a t e} / \%\end{array}$ \\
\hline \hline SRC & 32.70 & 185.00 & 187.90 & 282.10 & 5.90 & 1.11 & 3.10 \\
\hline TRC-SL & 24.80 & 202.00 & 239.80 & 416.40 & 9.80 & 4.98 \\
\hline TRC-BRB & 20.00 & 199.50 & 249.80 & 356.20 & 12.50 & 2.33 \\
\hline
\end{tabular}

can greatly improve the seismic performance of the specimen. The displacement ductility factor of specimen TRC-SL is smaller than TRC-BRB, but the hysteretic energy is larger, for the brace is destructed in advance so as to rapidly degenerate the strength and rigidity of specimen TRC-BRB. Thus the displacement ductility factor is increased and the capacity of dissipation energy is decreased.

\subsection{Equivalent Viscous Damping Ratio of Specimen}

The hysteretic damping of single-column pier and double-column pier is very different. The damping of singlecolumn pier comes from the inelasticity deformation of reinforced concrete, while the damping of double-column pier comes from the inelasticity of dissipation energy components and reinforced concrete. The equivalent viscous damping ratio of single-degree-of-freedom spring oscillator may be used to represent hysteretic damping. The equivalent viscous damping ratio is also the core indicator measuring the capacity of specimen dissipation energy and the indicator is defined as the ratio of monocyclic hysteretic energy to elastic strain energy, as is shown in formula (2).

$$
\begin{gathered}
\xi_{\mathrm{c}, \mathrm{h}}=\frac{A_{\mathrm{h}}}{2 \pi F_{\mathrm{m}} \Delta_{\mathrm{m}}}=\frac{A_{\mathrm{h}}}{4 \pi A_{\mathrm{c}}} \\
F_{\mathrm{m}}=\frac{1}{2}\left(\left|F_{\max }\right|+\left|F_{\min }\right|\right) \\
\Delta_{\mathrm{m}}=\frac{1}{2}\left(\left|\Delta_{\max }\right|+\left|\Delta_{\min }\right|\right)
\end{gathered}
$$

In formula (2)-(4): $A_{h}, A_{e}$ are respectively the area of hysteretic loop and triangular shadow. Their values equal respectively the weekly hysteretic energy and elastic strain energy, as is shown in Fig. (9).

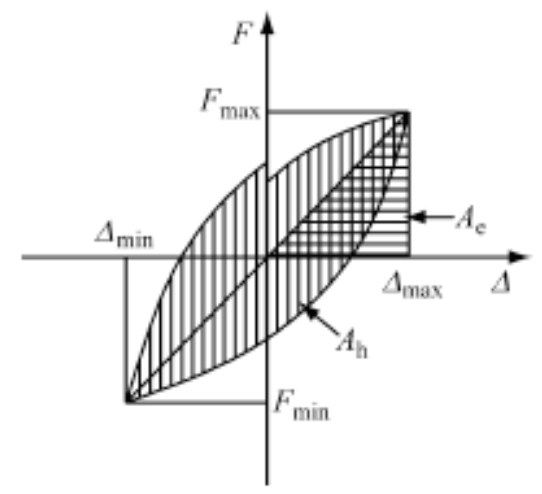

Fig. (9). Hysteretic Energy Dissipation.
As is shown in Fig. (10), when the damping ratio is proportional to loading displacement, the specimen TRC-BRB fluctuates more obviously. Due to the failure of brace, when the loading displacement is at $80 \mathrm{~mm}$, the damping ratio of specimen TRC-BRB begins to rapidly decrease, finally less than the damping ratio of single-column pier. With the increase of loading displacement, the damping ratio of specimen TRC-SL and SRC increases. Compared to specimen SRC, the maximum damping ratio of specimen TRC-SL is increased by about $44 \%$.

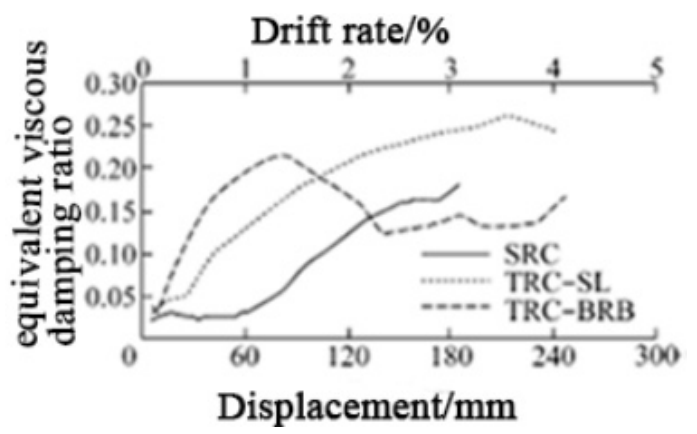

Fig. (10). Changes of equivalent viscous damping ratio when displacement differs.

\subsection{Deformation Capacity of Dissipation Energy Com- ponents}

The shear force of shearing-type connecting rode and axial force of buckling restrained brace can't be easily measured. It is also difficult to form the hysteretic curve with the same displacement as the force of dissipation energy components, so the horizontal force of pier top is utilized to replace the shear force or axial force of dissipation energy components. The deformation capacity of dissipation energy components can be evaluated by the shearing deformation of pier top horizontal force with dissipation energy components or the hysteretic curve of axial displacement. As is shown in Fig. (11), the hysteretic curve of shearing deformation of pier top horizontal force and connecting rode S4 (the forth row from the base), has a plump shape. The maximum shearing deformation is $14 \gamma_{y}$, and the deformation capacity is quite strong. As is shown in Table 2, the ductility factor of connecting rode next to pier top is the maximum, reaching 20 , and the deformation capacity is fully developed. The ductility factor of connecting rode next to pier bottom is quite small, for the relative deformation between the bottom of pier column is quite small. 


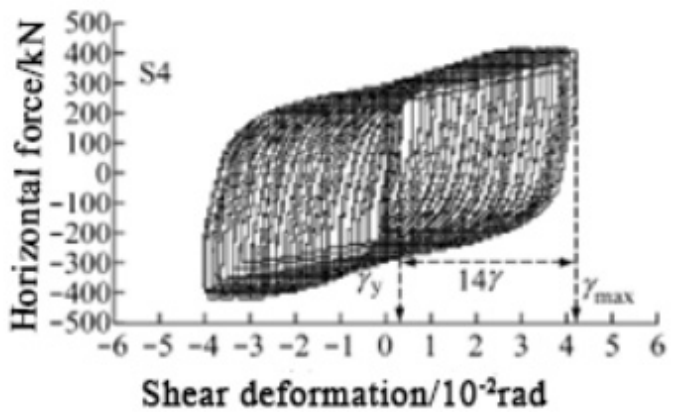

Fig. (11). Hysteretic Curve of Shearing Deformation of Horizontal Force And Connecting Rode S4.

Table 2. Ductility of shearing-type connecting rode.

\begin{tabular}{|c|c|c|}
\hline Shearing-type connecting rode & $\gamma_{\text {max }} / \mathbf{r a d}$ & $\gamma_{\text {max }} / \gamma_{\mathbf{y}}$ \\
\hline \hline $\mathrm{S}_{1}$ & 0.010 & 3 \\
\hline $\mathrm{S}_{2}$ & 0.016 & 4 \\
\hline $\mathrm{S}_{3}$ & 0.035 & 8 \\
\hline $\mathrm{S}_{4}$ & 0.042 & 14 \\
\hline $\mathrm{S}_{5}$ & 0.057 & 20 \\
\hline
\end{tabular}

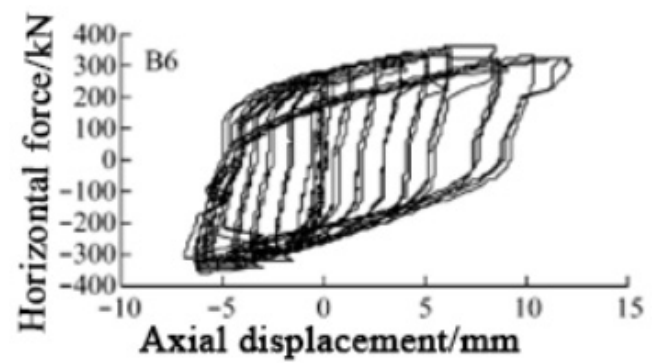

Fig. (12). Hysteretic Curve of Horizontal Force and Axial Displacement of Brace B6.

As is shown in Fig. (12), the hysteretic curve of the pier top horizontal force and the axial displacement of brace B6, has a plump shape. But the figure is asymmetric in positive and negative directions, which is quite different from the hysteretic curve of typical buckling restrained brace. The brace can be seen asymmetric in tension-compression direction, as the skeleton curve of specimen TRC-BRB has an asymmetric loading capacity in positive and negative directions. The ductility factors of brace are quite big and the deformation capacity is quite strong. The disadvantage is that the dissipation energy effect can't go on as the brace is destructed in advance. The ductility factor of brace B4 is the maximum, reaching 38 , because brace B4 never cracks in the test.

\section{CONCLUSION}

In conclusion, structural damage control may well enhance the safety of the bridge. The internal force and displacement of main components can be reduced correspondingly, so that the safety of long-span cable-stayed bridges is well protected.

\section{CONFLICT OF INTEREST}

The authors confirm that this article content has no conflict of interest.

\section{ACKNOWLEDGEMENTS}

Declared none.

\section{REFERENCES}

[1] J. Xie, "Research on Recognition Methods of Bridge Structure Damage Based on Vibration," South China University of Technology, 2003.

[2] J. Wei, "Research on Damping and Vibrational Isolation Measures of Highway-railway Long-span Cable-stayed Bridge," Lanzhou Jiaotong University, 2012.

[3] X. Kang, "Research on Damping and Vibrational Isolation and Analysis of Long-span Cable-stayed Bridge Response in Earthquake," Hefei University of Technology, 2012.

[4] W. Aiguo, "Analysis on the Dynamic Characteristics and Seismic Performance of Long-span Cable-stayed Bridge," Wuhan University of Technology, 2008.

[5] X. Li, "Research on Active Earthquake Response Control of Longspan Cable-stayed Bridge Structure," Hefei University of Technology, 2008

[6] T. A. N. Guan-jun, "The Structure Method and Application of Background Value in Grey System GM $(1,1)$ Model (I)" Systems Engineering-Theory \& Practice vol. 4, pp. 018, 2000.

[7] O. Humlum, A. Instanes, and J. L. Sollid, "Permafrost in Svalbard: a review of research history, climatic background and engineering challenges," Polar Research, pp. 191-215, 2003.

[8] A. R. Fersht, A. Matouschek, and L. Serrano, "The folding of an enzyme: I. Theory of protein engineering analysis of stability and pathway of protein folding," Journal of Molecular Biology, vol. 224, no. 3, pp. 771-782, 1992.

[9] Curtis, and M. Riehle, "Tissue engineering: the biophysical background." Physics in Medicine and Biology, vol. 46, no. 4, p. 47, 2001.

[10] L. Sun, W. Jun, and X. Wen, "Experimental Investigation on Energy Dissipation SSubsidiary Subsidiary Piers for Long Span Cable-Stayed Bridges," In: $15^{\text {th }}$ World Conference on Earthquake Engineering, 2012.

[11] R. S. Murch, L. Abbott, "Establishing the Quantitative Basis for Sufficiency Thresholds and Metrics for Friction Ridge Pattern Detail and the Foundation for a Standard," US Department of Justice and National Institute of Justice, Washington DC, 2012.

Received: February 03, 2015

Revised: April 03, 2015

Accepted: May 25, 2015

(C) Ning Wan; Licensee Bentham Open.

This is an open access article licensed under the terms of the (https://creativecommons.org/licenses/by/4.0/legalcode), which permits unrestricted, noncommercial use, distribution and reproduction in any medium, provided the work is properly cited. 